\title{
Determinants of Adherence to Recommendations of the Dietary Approach to Stop Hypertension in Adults with Hypertension Treated in a Hospital in Benin
}

\author{
Nikiema Leon ${ }^{1}$, Sossa Charles ${ }^{1, *}$, Agueh Victoire D. ${ }^{1}$, Dedewanou Magloire ${ }^{2}$, Metonnou Clemence ${ }^{1}$, \\ Colette Azandjeme ${ }^{1}$, Noel M. Paraiso ${ }^{1}$, Ouedraogo T. Laurent ${ }^{3}$, Michel Makoutode ${ }^{4}$, Houinato Dismand ${ }^{5}$ \\ ${ }^{1}$ Department of Health Promotion, Regional Institute of Public Health, University of Abomey-Calavi, Benin \\ ${ }^{2}$ Hospital Saint Luc, Benin \\ ${ }^{3}$ Department of Epidemiology and Biostatistics, Regional Institute of Public Health, University of Abomey-Calavi, Benin \\ ${ }^{4}$ Department of Health and Environment, Regional Institute of Public Health, University of Abomey-Calavi, Benin \\ ${ }^{5}$ Department of Medicine and Specialities, Faculty of Health Sciences, University of Abomey-Calavi, Benin
}

Copyright $(\mathcal{C} 2015$ by authors, all rights reserved. Authors agree that this article remains permanently open access under the terms of the Creative Commons Attribution License 4.0 International License

\begin{abstract}
The dietary approach to stop hypertension (DASH) is an effective nutritional strategy to prevent and treat cardiovascular disease. Optimal benefit from dietary recommendations in management of hypertension depends on the compliance. This analytic cross sectional study aimed at establishing determinants of DASH among adults with hypertension treated at hospital in Benin. The study included 150 hypertensive adults selected during medical visit for blood pressure monitoring at hospital Saint-Luc in Cotonou from June $3^{\text {rd }}$ to July $1^{\text {st }}$, 2014. Data on consumption of sodium, fruits and vegetables, alcohol, saturated and trans fat rich products were collected by questionnaire. A score of adherence to DASH was built. Determinants of adherence to DASH were identified using logistic regression model. Only $20 \%$ of subjects showed adherence to DASH. Better knowledge on hypertension $\mathrm{OR}=5.18$ (95\%IC 1.98-13.22) and healthy dietary habits and lifestyle prior to diagnosis of hypertension $\mathrm{OR}=4.26(95 \% \mathrm{IC} 1.67-13.18)$ increased the likelihood of adherence to dietary recommendations for hypertension management. Nutrition education and information of patients on hypertension and its complications during medical consultations may increase their adherence to dietary recommendations for management of the disease.
\end{abstract}

Keywords Adherence, DASH, Hypertension, Adults, Benin

\section{Introduction}

Prevalence of hypertension (blood pressure $\geq 140 / 90$ $\mathrm{mmHg}$ ) in adult population worldwide was $29.2 \%$ in men and $24.8 \%$ among women in 2012. According to a recent WHO report, over $40 \%$ of adults in many African countries have hypertension [1]. Globally, hypertension is the leading risk factor, because it causes $13 \%$ of deaths worldwide. Hypertension is the leading cause of stroke among Sub-Saharan Africans [2]. In Africa region, stroke is the dominant form of cardiovascular disease (CVD) [3]. Mortality from stroke varies from 38 to $56 \%$ according to ischemic or hemorrhagic type [4].

In Benin, prevalence of hypertension increased from $28.4 \%$ in 2008 to $38.7 \%$ in 2011 with a predominance in urban areas [5]. Despite the availability of effective anti-hypertensive medications, hypertension remains generally poorly controlled in almost half of cases [6-9].

A recent systematic review and meta-analysis of randomized controlled trials confirmed that the "Dietary Approach to Stop Hypertension" (DASH) is an effective nutritional strategy to prevent and treat cardiovascular disease as it induces a significant decrease in systolic and diastolic blood pressure and improves other cardiometabolic risk factors [10-12]. The DASH diet aims at reducing blood pressure by promoting diet rich in fruits and vegetables, whole grains, low fat dairy products, legumes / beans, low sodium and added sugars [13-15]. A recent systematic review of nine intervention studies on adherence to the DASH diet showed low adherence whereas the optimal benefit of this diet depends on medium and long-term compliance [16]. Increased adherence to DASH diet was associated with older age and lower waist circumference according to Barak et al. [17]. In the study conducted by Epstein et al. [18], ethnicity predicted dietary adherence, with African Americans less adherent to DASH diet compared to whites. No other demographic, behavioral, or social variable predicted DASH adherence. 
In Benin, only $4.8 \%$ of hypertensive patients are under pharmacological treatment and less than half $(1.9 \%)$ had controlled blood pressure [19]. The objective of this study was to identify determinants of adherence to DASH in patients with hypertension treated at hospital in Benin.

\section{Materials and Methods}

\subsection{Study Design}

This was a cross-sectional study which was conducted in the cardiology unit of care and research at hospital Saint-Luc in Cotonou, capital of Benin.

\subsection{Study Population}

The target populations included patients with diagnosed hypertension BP (systolic $\mathrm{BP}>140 \mathrm{~mm} \mathrm{Hg}$ or diastolic $\mathrm{BP}>$ $90 \mathrm{~mm} \mathrm{Hg}$ ) under pharmacological treatment in the service of Cardiology in Saint-Luc hospital in Cotonou. The study included patients in the "active file" of one physician. At the diagnosis, patients were provided once with written nutritional advises.

\subsection{Sample Size}

The minimum required sample size was estimated by considering theoretical prevalence of adherence to nutritional recommendations in hypertensive patients at $65 \%$ [9], precision at 0.08 and adding $10 \%$ of non-responders. The sample size was 150 participants. Subjects were selected among patients already with diagnosis of hypertension as they came to hospital for the blood pressure monitoring.

\subsection{Inclusion Criteria}

Hypertensive patients aged 18 and over diagnosed for hypertension at least one month earlier and under pharmacological treatment with at least one follow-up visit in the Hospital Saint Luc of Cotonou were included in the study.

\subsection{Exclusion Criteria}

Patients that met inclusion criteria listed above but who were health professionals (medical and paramedical) or unable to undergo the interview were excluded from the study.

\subsection{Study Variables}

\subsubsection{Dependent Variable}

The dependent variable was the adherence to DASH regarding behavioral risk factors [20], some principles of DASH [16] and other risk factors associated to hypertension.

According to the literature, studies used varied methodologies to assess adherence to DASH recommendations:

- DASH scores based on estimates of dietary intakes above or below the median considering gender and energy intake using validated frequency questionnaire [21].

- DASH scores based on individuals consuming at or above the recommended number of servings for food groups considered [18]

- DASH adherence based on urinary excretion of sodium and potassium [22].

In the present study we used a fixed serving of validated Benin's food guide [23] as reference for assessing dietary adherence for all subjects since no validated food frequency questionnaire were available and urinary excretion method is time and resource-consuming.

Considered dietary recommendations for hypertension management in the present study were following:

- Reducing of sodium intake,

- Consuming at least five servings of fruits and vegetables a day;

- Reducing alcohol consumption;

- Reducing the consumption of trans-fat or animal source saturated fat-rich foods [24-26].

Reduction of sodium intake was appreciated by the reduction of frequency of consumption of salt rich-foods: canned meats, crackers, salted dried fish, ready cocked meal, as well the use of savory broths called "cube" in food preparation and the use of salt at dining table.

To assess the amount of consumed fruits and vegetables, we use food frequency questionnaire and we considered as reference the patient's typical week (according to STEPS) [27] and we considered serving estimation as described in Benin's food guide [23].

Limitation of alcohol consumption was defined as the absence of excessive-drinking ( $\leq 2$ standard drinks of local alcohol or imported alcoholic beverages for men and $\leq 1$ for women per day) $[28,29]$.

Reducing consumption of saturated and trans fats refers to the non-use of animal source fat as cooking oil, limitation of the consumption of candy and cakes at most twice a week, the absence of multiple firings $(>2)$ with the same oil.

One dietary recommendation was satisfied if all criteria regarding the recommendation are met. The score of "1" was assigned if one dietary recommendation was satisfied and " 0 " in all other cases. The score of adherence to dietary recommendations was the total score obtained for each participant $[16,30]$. The adherence score ranged from 0 to 4 . A score of 4 meant that the four dietary recommendations were met.

\subsubsection{Independent Variables}

Independent variables were:

- Patient-related factors: age, sex, marital status, religion, education level, occupation, family history of hypertension, body mass index, diet and lifestyle prior 
the diagnosis of hypertension, family support, social assistance and income proxy.

- Factors related to hypertension: blood pressure, disease duration, and presence of comorbidities, presence of hypertension symptoms, number of follow-up visits, type of treatment, impact of the treatment and knowledge on hypertension that was assessed through questions on the basic mechanism underlying hypertension (the force of blood against the wall of the arteries), contributing factors to hypertension, complications of untreated hypertension and treatments for hypertension.

\subsection{Data Collection Procedures}

Data were collected in interview using questionnaires from $3^{\text {rd }}$ June to $1^{\text {st }}$ July 2014. The investigator conducted one day training to orientate the interviewers on data collection and to standardize the whole process. Questionnaires were pre-tested in other hospital by checking the answerability and the appropriateness of questions. The duration of the interview was quantified to not make uncomfortable participants as they were interviewed after appointment with the cardiologist. The result of the pre-test informed the investigator on the required adjustments in the questionnaire. The interviews were conducted in the local language (Fon) and in French by interviewers.

\subsection{Data Analysis}

Data were analyzed using Statistical Package for Social Studies (SPSS) software, version 18.0 (SPSS Inc., Chicago, IL). Pearson Chi-square test was used to compare proportions of subjects that met DASH recommendations according to independent variables. Student "t" test for independent samples was used to compare blood pressure between adherent and non-adherent groups. Factors associated with adherence to DASH in univariate analysis at the 0.20 significance level were introduced in a logistic regression model to identify determinants of adherence. The significance level was set at $\mathrm{p}<0.05$.

\subsection{Ethical Considerations}

The objectives of the study were explained to participants. Free and informed oral consent was obtained before starting the interview. This consent claims that participants are not at risk by refusing to participate in the survey or stopping their collaboration during the study. The confidentiality and anonymity of the information collected were ensured.

\section{Results}

\subsection{Characteristics of Subjects}

Among the 150 subjects included in the study, women represented $63.3 \%$. Participants aged $35-54$ years represented $42 \%$ and at least one hypertension symptom was present in $56.67 \%$. Proportions of subjects with no schooling and those who showed low knowledge on hypertension were $15.3 \%$ and $69.33 \%$ respectively. Overweight was observed in $45.33 \%$ of patients. Means of blood pressure in participants were $135.10 \pm 0.61 \mathrm{mmHg}$ (systolic blood pressure) and $79.90 \pm 0.5 \mathrm{mmHg}$ (diastolic blood pressure).

\subsection{Adherence to DASH}

Table 1 summarizes adherences scores to DASH. The mean score was $1.9 \pm 1.2$ and the median score was 2 . Among the 150 participants, $20 \%,(n=30)$ fulfilled all of the four dietary recommendations. Proportion of men who complied with the four dietary recommendations was higher than in women $(\mathrm{p}=0.011)$.

Table 1. Distribution of participants according to scores of adherence to DASH in hospital Saint Luc in Cotonou, Benin 2014

\begin{tabular}{ccccc}
\hline \multirow{2}{*}{$\begin{array}{c}\text { Scores of } \\
\text { adherence to } \\
\text { DASH }\end{array}$} & $\begin{array}{c}\text { Women } \\
\text { (N=95) } \\
(\mathbf{n ~ \% )}\end{array}$ & $\begin{array}{c}\text { Men (N=55) } \\
\mathbf{( n ~ \% )}\end{array}$ & p & $\begin{array}{c}\text { Sex } \\
\text { Total } \\
\mathbf{n}(\mathbf{1 5 0})\end{array}$ \\
\hline 4 & $13(8,7)$ & $17(11,3)$ & $\mathbf{0 . 0 1 1}$ & $\mathbf{3 0}(\mathbf{2 0 , 0 )}$ \\
3 & $10(6,7)$ & $7(4,7)$ & 0.682 & $17(11,3)$ \\
2 & $36(24,0)$ & $15(10,0)$ & 0.185 & $51(34,0)$ \\
1 & $34(22,7)$ & $11(7,3)$ & $\mathbf{0 . 0 4 2}$ & $45(30,0)$ \\
0 & $2(1,3)$ & $5(3,3)$ & 0.050 & $7(4,7)$ \\
\hline
\end{tabular}

Table 2 describes the compliance with each dietary recommendation. Sufficient consumption of fruits and vegetables and limitation of alcohol intake showed the lowest and the highest adherence respectively. Furthermore, mean of servings in participants who met fruit and vegetables consumption recommendation was $2.23 \pm 0.73$ (servings of fruit per day) and $3.41 \pm 0.77$ (servings of vegetables per day). All of participants used at least one anti-hypertensive drug. Moreover, mean of systolic blood pressure was slightly lower in participants who met dietary recommendations compared to counterparts: $130.39 \pm 0.7$ versus $138.41 \pm 0.8(\mathrm{p}=0.20)$ for systolic blood pressure and $79.81 \pm 0.6$ versus $80.01 \pm 0.5(\mathrm{p}=0.062)$ for diastolic blood pressure.

Table 2. Compliance with DASH in adults with hypertension treated in Saint Luc Hospital of Cotonou, Benin, 2014

\begin{tabular}{ccc}
\hline \multirow{2}{*}{ Dietary recommendations } & \multicolumn{2}{c}{ Adherence (\%) } \\
\cline { 2 - 3 } & Yes & No \\
\hline Reducing of sodium intake & 36.67 & 63.33 \\
$\begin{array}{c}\text { Reducing alcohol consumption } \\
\begin{array}{c}\text { Consuming at least five servings of } \\
\text { fruits and vegetables a day }\end{array}\end{array}$ & 90.67 & 09.33 \\
$\begin{array}{c}\text { Reducing the consumption trans-fat or } \\
\text { animal sources of saturated fat-rich food }\end{array}$ & 64.67 & 80.00 \\
\hline
\end{tabular}




\subsection{Factors Associated with Adherence to DASH}

Tables 3 and 4 describe relations between participant's characteristics and adherence to DASH. Sex, occupation, matrimonial status, socioeconomic level, dietary habits and lifestyle prior to diagnosis of hypertension, knowledge on hypertension, presence of symptoms of hypertension, frequency of blood pressure monitoring, type of treatment and impact of treatment according to patient were associated with adherence to DASH in participants at significance level $\mathrm{p}<0.20$.

\subsection{Odds Ratio of Adherence to DASH}

Among factors associated to compliance with DASH in subjects with hypertension, table 5 shows that only dietary habits and lifestyle prior to diagnosis of hypertension and knowledge on hypertension remained significantly associated in logistic model. Impact of treatment according to patient tended to be associated with compliance with dietary recommendations.

Table 3. Sociodemographic factors associated with adherence to DASH in patients with hypertension treated at Saint Luc hospital, univariate analysis, Cotonou, Benin 2014

\begin{tabular}{|c|c|c|c|c|}
\hline \multirow{2}{*}{$\begin{array}{l}\text { Sociodemographic and } \\
\text { medical characteristics }\end{array}$} & \multirow{2}{*}{$\begin{array}{l}\text { Total } \\
\mathrm{N}(\%)\end{array}$} & \multicolumn{2}{|c|}{ Adherence to DASH } & \multirow[b]{2}{*}{$\mathrm{p}$-value } \\
\hline & & $\begin{array}{c}\text { No } \\
(n=120)\end{array}$ & $\begin{array}{c}\text { Yes } \\
(n=30)\end{array}$ & \\
\hline \multicolumn{5}{|l|}{ Age (years) } \\
\hline$<45$ & $27(18.0)$ & 24 & 3 & \multirow{3}{*}{0.265} \\
\hline $45-64$ & $91(60.7)$ & 73 & 18 & \\
\hline$\geq 65$ & $32(21.3)$ & 23 & 9 & \\
\hline \multicolumn{5}{|l|}{ Sex } \\
\hline Women & $95(63.3)$ & 82 & 13 & \multirow{2}{*}{$0.013^{*}$} \\
\hline Men & $55(36.7)$ & 38 & 17 & \\
\hline \multicolumn{5}{|l|}{ Matrimonial status } \\
\hline Married & $112(74.7)$ & 86 & 26 & \multirow{2}{*}{$0.100 *$} \\
\hline $\begin{array}{l}\text { Unmarried } \\
\text { Religion }\end{array}$ & $38(25.3)$ & 34 & 4 & \\
\hline Christians & $118(78.7)$ & 95 & 23 & \multirow{2}{*}{0.765} \\
\hline Non-Christian & $32(21.3)$ & 25 & 7 & \\
\hline \multicolumn{5}{|l|}{ Education } \\
\hline $\begin{array}{c}\text { Primary, secondary or } \\
\text { high school }\end{array}$ & $127(84.7)$ & 99 & 28 & \multirow[t]{2}{*}{0.158} \\
\hline No schooling & $23(15.3)$ & 21 & 2 & \\
\hline \multicolumn{5}{|l|}{ Occupations } \\
\hline Salaried workers & $67(44.7)$ & 49 & 18 & \multirow[b]{2}{*}{$0.062 *$} \\
\hline $\begin{array}{c}\text { Self-employment } \\
\text { /houses wives }\end{array}$ & $83(55.3)$ & 71 & 12 & \\
\hline \multicolumn{5}{|l|}{$\begin{array}{l}\text { Family support and } \\
\text { social assistance }\end{array}$} \\
\hline Sufficient & $124(82.7)$ & 95 & 29 & \multirow{2}{*}{$0.051 *$} \\
\hline Poor & $26(17.3)$ & 25 & 1 & \\
\hline \multicolumn{5}{|l|}{ Socioeconomic level } \\
\hline High & $55(36.7)$ & 39 & 16 & \multirow{3}{*}{$0.106^{*}$} \\
\hline Medium & $55(36.7)$ & 47 & 8 & \\
\hline Low & $40(26.6)$ & 34 & 6 & \\
\hline
\end{tabular}

*p-value 0.20 for Pearson Chi-square
Table 4. Hypertension related factors associated with adherence to DASH in patients with hypertension treated at Saint Luc hospital, univariate analysis, Cotonou, Benin 2014

\begin{tabular}{|c|c|c|c|c|}
\hline \multirow{2}{*}{$\begin{array}{l}\text { Sociodemographic and } \\
\text { medical characteristics }\end{array}$} & \multirow{2}{*}{$\begin{array}{l}\text { Total } \\
\mathrm{N}(\%)\end{array}$} & $\begin{array}{l}\text { Adher } \\
\text { DA }\end{array}$ & $\begin{array}{l}\text { ice to } \\
\mathrm{H}\end{array}$ & \multirow{2}{*}{ p-value } \\
\hline & & $\begin{array}{c}\text { NO } \\
(n=120)\end{array}$ & $\begin{array}{c}\text { YES } \\
(n=30)\end{array}$ & \\
\hline
\end{tabular}

Diseases associated

with hypertension

$$
\text { Yes (diabetes, }
$$

dyslipemia, obesity)

Presence of symptoms

of hypertension

$$
\text { Yes }
$$$$
\text { No }
$$

$65(43.3)$

66

19

0.411

Frequency of blood

pressure monitoring

$\begin{array}{llc}\leq 4 \text { visits/year } & 131(87.3) & 102 \\ <4 \text { visits/year } & 19(12.7) & 18\end{array}$

$0.120 *$

Family history of hypertension

$\begin{array}{cccc}\text { Yes } & 101(67.3) & 83 & 18 \\ \text { No } & 49(32.7) & 37 & 12 \\ \text { BMI ** } & & & \end{array}$

0.340

BMI **

$18.5-24.9$
$25-29.9$
$>30$

$\begin{array}{lll}53(35.6) & 90 & 14 \\ 68(45.6) & 56 & 12 \\ 28(18.8) & 24 & 4\end{array}$

Type of treatment

Modern Medicine
Modern and traditional
medicine

$93(62.0)$

$57(38.0)$

70

$0.069^{*}$

Impact of treatment

according to patient

No improvement

53(35.3)

50

Improvement

97(64.7)

70

3

Dietary habits and

lifestyle prior to

diagnosis of

hypertension

$$
\begin{aligned}
& \text { Healthy } \\
& \text { Unhealthy }
\end{aligned}
$$

$\begin{array}{ll}43(28.7) & 25 \\ 107(71.3) & 95\end{array}$

18

$0.001 *$

Knowledge on

hypertension

Good enough

Weak

Time since

hypertension

diagnosis

$<3$ years

$65(43.3)$

53

12

$\geq 3$ years

$85(56.7)$

67

0.681 
Table 5. OR of adherence to DASH in patients with in hypertension treated at Saint Luc Hospital in Cotonou, multivariate analysis, Benin 2014

\begin{tabular}{cccc}
\hline \multirow{2}{*}{ Factors } & \multicolumn{3}{c}{ Adherence to DASH } \\
\cline { 2 - 3 } & OR & CI95\% & p-value \\
\hline $\begin{array}{c}\text { Dietary habits and lifestyle } \\
\text { prior to diagnosis of } \\
\text { hypertension } \\
\text { Unhealthy }\end{array}$ & & & \\
Healthy & 1 & & \\
Knowledge on hypertension & 4.26 & $1.67-$ & 0.002 \\
$\quad$ Weak & 1 & 13.18 & \\
$\quad$ Good enough & 5.18 & $1.98-$ & $<0.000$ \\
Impact of treatment according & & 13.22 & \\
$\quad$ to patient & & & \\
Improvement & 1 & & \\
No improvement & 3.49 & $0.92-13.18$ & 0.065 \\
\hline
\end{tabular}

\section{Discussion}

The study examined the determinants adherence to DASH in patients with hypertension treated at hospital. Only $20 \%$ of patients showed adherence to DASH. Knowledge on hypertension and associated complications, lifestyle and eating habits prior to diagnosis hypertension were independent determinants of adherence to DASH.

\subsection{Adherence to DASH}

Adherence to DASH was low as reported Kwan et al. in a systematic review [16]. Racine et al. [31] reported in their study that only $21 \%$ of participants achieved the objectives of DASH for fruits, vegetables and saturated fat, after dietary counseling in randomized intervention study over a period of three months. In contrast, Uzun et al. in a study conducted in 2009 in Turkey on adherence to treatment and dietary recommendations and lifestyle, reported $35 \%$ of non-adherent to such recommendations [9]. This difference could be explained by differences in study methods. Indeed Uzun et al. did not address only the nutritional aspects of the management of hypertension but the authors explored simultaneously adherence to drug therapy, dietary recommendations, physical activity, self-measurement of blood pressure and smoking cessation. Moreover, in the study of Uzun et al., [9], adherence to dietary recommendations was explored in one question that was: do you respect dietary regimen for hypertension? (salt and cholesterol). For this question, patients generally tend to say yes without one actually knows what they respect as advice and what is not.

In the present study, recommendation regarding adequate consumption of fruits and vegetables ( $\geq 5$ servings a day) seemed to be difficult to meet. Indeed, only $20 \%$ of patients had adequate consumption of fruits and vegetables. This result was close to those of the STEPS survey in 2008 which reported $21.95 \%$ of sufficient consumption of fruits and vegetables with an average consumption of 2.10 servings per day [27].

In addition to the consumption of fruits and vegetables, recommendation relative to salt intake reduction was also less met. This, clearly, indicated the efforts needed to achieve adherence to dietary recommendation to stop hypertension. It was noted with time, decreased adherence to the DASH diet in some studies $[31,32]$ suggesting the need to maintain adherence to specific dietary recommendation.

\subsection{Factors Associated with Adherence to DASH}

Sufficient knowledge on hypertension increased the likelihood of adherence to DASH. This was consistent with results found by Uzun et al. [9]. A better understanding of hypertension induces better risk perception for adherence to DASH based on health belief theory. According to theory of reasoned action to change behavior, humans are usually rational and logical, and they use systematically available information. Humans consider the consequences of their actions before deciding whether or not they adopt a certain behavior [33]. According to literature, knowledge, attitudes and beliefs are individual factors that influence the behavior of individuals [34]. The understanding of hypertension and awareness of its complications allow patients making efforts to adhere to DASH that intended to contribute to blood pressure reduction.

Healthy lifestyle and eating habits include: no smoking, consuming less than $50 \mathrm{~g}$ of alcohol per week, moderate to intense physical activity at least 3 times a week, eating vegetables every day, maintain a normal weight $(\mathrm{BMI}<25 \mathrm{~kg}$ $/ \mathrm{m}^{2}$ ) [25], all will affect how long we can avoid experiencing chronic disease. These behavioral factors (diet, physical activity, smoking, and alcohol abuse) are largely involved in the nutritional transition process [35] and are close to DASH. A subject who adopted healthy lifestyle and eating habits would have less difficulty to adhere to DASH involved in the study.

According to the transtheoretical behavior change model, at any given time, a person is in one of five stages of change: precontemplation, contemplation, preparation, action, or maintenance. At the stage of action, the person has adopted healthy dietary habits and lifestyle. Once he has practiced the new behavior change for at least six months, he is in the maintenance stage and works to prevent relapse and integrate the change into his life [36]. At this stage, it should subsequently be easy to adhere to dietary recommendation to reduce blood pressure.

\subsection{Education, Socioeconomic Status and Social Support Were Not Independent Determinants of Adherence to DASH}

In multivariate model, education, income and social support were not independent determinants of adherence to DASH. This result was in agreement with those reported by 
Epstein et al. in a study conducted in 2012 focussing on determinants and consequences of adherence to the DASH diet among African-Americans and Caucasians with hypertension [18]. Indeed, authors found that subjects with low "perceived social support" and "perceived control" over their condition showed the lowest adhesion scores. However, no psychosocial variable predicted adherence to the DASH diet [18]. Similarly, although studies have reported the association of socioeconomic status and the adoption of health-promoting behaviors [37], Epstein et al. found that this factor was not predictive of adherence to the DASH diet [18].

Other studies reported the link between education and the adoption of healthy behaviors such as increased physical activity, stopping smoking, reducing sodium intake and alcohol [37]. However, this factor was not shown as a determinant of adherence to the DASH diet in the study conducted by Epstein et al. [18]. Uzun et al. [9] at contrast, observed a link between education, income and adherence to dietary recommendations. This difference in results may be due to the specificity of study methods used in both cases. For the "education factor" for example, we considered two groups of participants in the analysis: no schooling and primary to high school. But for the same factor, Uzun et al. [9] grouped the patients by non-literate, literate without a diploma, graduates of elementary, high school graduates and university graduates. Furthermore, education and economic status are often associated with the acquisition of knowledge and better understanding of diseases and allow awareness consequences. In our study, the level of knowledge about the disease that emerged as an independent determinant of adherence was probably explained by education and economic status.

Although there is no consensus on the best way to assess adherence to DASH diet $[16,30]$, limitation of this study was related to the way that the collection of data on dietary habits in connection with the adherence to DASH relies partly on subjectivity [19]. The four dietary recommendations were equally weighted when assessing the adherence while it is possible that recommendations did not have exactly the same effect on blood pressure $[18,19]$. DASH recommendations in terms of food servings vary based on energy requirements but a fixed serving from validated local food guide was used as reference for assessing dietary adherence for overweight and normal subjects. Proportion of adherence and non-adherence to DASH ( $20 \%$ vs $80 \%)$ was unequal. Thus, the statistical test could detect OR of 1.8 and above with a power of 0.80 [38].

\section{Conclusions}

Adherence to DASH in patients with hypertension treated at Saint Luc hospital in Cotonou was suboptimal. Consuming at least five servings of fruits and vegetables a day was the least met recommendation. Nutrition education and information to patients about hypertension during medical consultations are important to increase their adherence to the dietary recommendation for the management of the disease.

\section{Conflicts of Interest}

The authors declare no conflict of interest.

\section{Acknowledgements}

The authors thank the authorities of the Hospital St. Luc of Cotonou, the staff of the Cardiology Unit and the participants in the study.

\section{REFERENCES}

[1] World Health Organization, Chronic diseases, WHO, Geneva, 2012.

[2] World Health Organization, Global health risks: mortality and burden of disease attributable to selected major risks, World Health Organization, Geneva, 2009.

[3] T.A Gaziano, Reducing the growing burden of cardiovascular disease in the developping word. Health Affairs. Vol 26, 13-24. 20007

[4] L. Fourcade, P. Paule, B. Mafart, [Arterial hypertension in sub-Saharan Africa. Update and perspectives], Med. Trop. (Mars). Vol.67, $\mathrm{N}^{\circ}$ 6, 559-567. 2007

[5] World Health Organization, Non communicable diseases (NCT): Profil de Pays., 2011.

[6] J. Blacher, J. Halimi, O. Hanon, J. Mourad, A. Pathak, B. Schnebert, Management of hypertension in adults. French society of hypertension, 2013.

[7] J. Mourad, M. Zuber, X. Girerd, Goals 2015, 70\% of hypertension controlled: The reasons for this ambition and the means to achieve it, Ministry of Labor, Employment and Health. French, 2012.

[8] L. Rigal, H. Falcoff, Z. Rahy, P. Flores, M. Saurel-Cubizolles, V. Ringa, No lifestyle recommendations given to hypertensive patients. Characteristics of patients and their caregivers, Glob Health Promot. Vol.20 (Supp. 2), $\mathrm{N}^{\circ} 33-42.2013$

[9] Ş. Uzun, B. Kara, M. Yokuşoğlu, F. Arslan, M.B. Yılmaz, H. Karaeren, The assessment of adherence of hypertensive individuals to treatment and lifestyle change recommendations, Anadolu Kardiyol. Derg. Vol.9, $\mathrm{N}^{\circ} 2,102-109.2009$

[10] Z. Mokhtari, S. Hosseini, R. Miri, A.R. Baghestani, M. Zahedirad, M. Rismanchi, J. Nasrollahzadeh, Relationship between Dietary Approaches to Stop Hypertension score and Alternative Healthy Eating Index score with plasma asymmetrical dimethylarginine levels in patients referring for coronary angiography, J Hum Nutr Diet. Vol. 28, $\mathrm{N}^{\circ} 4$, 350-356. 2015. 
[11] M. Niknam, M. Saadatnia, F. Shakeri, A.H. Keshteli, P. Saneei, A. Esmaillzadeh, Adherence to a DASH-Style Diet in Relation to Stroke: A Case-Control Study, J Am Coll Nutr. Vol 31, 1-8. 2015

[12] L. Schwingshackl, G. Hoffmann, Diet Quality as Assessed by the Healthy Eating Index, the Alternate Healthy Eating Index, the Dietary Approaches to Stop Hypertension Score, and Health Outcomes: A Systematic Review and Meta-Analysis of Cohort Studies, J Acad Nutr Diet Vol. 115, $\mathrm{N}^{\circ} 5,780-800.2015$.

[13] F.J. He, J. Li, G.A. Macgregor, Effect of longer term modest salt reduction on blood pressure: Cochrane systematic review and meta-analysis of randomized trials, BMJ Vol.3, No346, f1325. 2013

[14] P. Saneei, A. Salehi-Abargouei, A. Esmaillzadeh, L. Azadbakht, Influence of Dietary Approaches to Stop Hypertension (DASH) diet on blood pressure: A systematic review and meta-analysis on randomized controlled trials, Nutr Metab Cardiovasc Dis Vol.2, Nº. Supp (12) 1253-1261. 2014

[15] M. Siervo, J. Lara, S. Chowdhury, A. Ashor, C. Oggioni, J.C. Mathers, Effects of the Dietary Approach to Stop Hypertension (DASH) diet on cardiovascular risk factors: a systematic review and meta-analysis, Br. J. Nutr. Vol. 28, 1-15. 2013

[16] M.W. Kwan, M.C. Wong, H.H. Wang, K.Q. Liu, C.L. Lee, B.P. Yan, C.M. Yu, S.M. Griffiths, Compliance with the Dietary Approaches to Stop Hypertension (DASH) diet: a systematic review, PLoS One Vol. 8, $\mathrm{N}^{\circ} 10$, e 78412. doi: 10.1371/journal.pone.0078412. 2013.

[17] F. Barak, E. Falahi, A.H. Keshteli, A. Yazdannik, A. Esmaillzadeh. Adherence to the Dietary Approaches to Stop Hypertension (DASH) diet in relation to obesity among Iranian female nurses. Public Health Nutr. Vol.18, $\mathrm{N}^{\circ} 4,1-8$, 2014

[18] Epstein D.E, Sherwood A, Smith P.J, Craighead L, Caccia C, Lin PH, Babyak M.A, Johnson J.J, Hinderliter A, Blumenthal A.A, Determinants and Consequences of Adherence to the DASH Diet in African American and White Adults with High Blood Pressure: Results from the ENCORE Trial, J Acad Nutr Diet. Vol. 112, $\mathrm{N}^{\circ}$ 11, 1763-1773. 2012

[19] D.S. Houinato, A.R. Gbary, Y.C. Houehanou, F. Djrolo, M. Amoussou, J. Segnon-Agueh, A. Kpozehouen, R. Salamon, Prevalence of hypertension and associated risk factors in Benin, Rev. Epidemiol. Sante Publique Vol. 60, $\mathrm{N}^{\circ}$ 2, 95-102. 2012-198. 2010

[20] World Health Organization, World Overview of Hypertension. A "silent killer" responsible for a global public health crisis, WHO, Geneva, 2013.

[21] E.M. Jones-McLean, B. Shatenstein, S.J. Whiting, Dietary patterns research and its applications to nutrition policy for the prevention of chronic disease among diverse North American populations, Appl Physiol Nutr Metab Vol. 35, $\mathrm{N}^{\circ} 2,195$

[22] CA. Nowson, N. Wattanapenpaiboon, A. Pachett. Low-sodium dietary approaches to stop hypertension-type diet including lean red meat lowers blood pressure in postmenopausal women. Nutr Res 29: $\mathrm{N}^{\circ} 1,8-18,2009$. doi: 10.1016/j.nutres.2008.12.002

[23] S. Levesque, H. Delisle, V. Agueh. Contribution to the development of a food guide in Benin: linear programming for the optimization of local diets. Public Health Nutr., Vol.18 $\mathrm{N}^{\circ} 4: 1-10.2013$

[24] S.R. Craddick, P.J. Elmer, E. Obarzanek, W.M. Vollmer, L.P. Svetkey, M.C. Swain. The DASH diet and blood pressure. Curr Atheroscler Rep. Vol.5, Nº, 484-91. 2003.

[25] H.W. Cohen, M.H. Alderman, Sodium, blood pressure, and cardiovascular disease, Curr. Opin. Cardiol. Vol. 22, $\mathrm{N}^{\circ} 4$, 306-310. 2007

[26] P. Jousilahti, Y. Wang, G. Hu, J. Tuomilehto, R. Antikainen, Lifestyle traits predict the development of hypertension: a large prospective population-based cohort study in Finland, Eur. Heart J. Vol. 33 (Abstract Supplement) 952-953. 2012

[27] Republic of Benin, Final report of STEPS survey in Benin, Cotonou, 2008.

[28] I.B. Puddey, L.J. Beilin, Alcohol is bad for blood pressure, Clin. Exp. Pharmacol. Physiol. Vol. 33, Nº 9 847-852. 2006

[29] W. Sinkiewicz, M. Weglarz, [Alcohol and wine and cardiovascular diseases in epidemiologic studies], Przegl. Lek. Vol. 66, $\mathrm{N}^{\circ}$ 5, 233-238. 2009

[30] E. Jones-McLean, J. Hu, L. S. Greene-Finestone, M. de Groh. Regime DASH et risque de cancer colorectal chez les adultes canadiens. Promotion de la sante' et pre'vention des maladies chroniques au Canada. Vol 35, $\mathrm{N}^{\circ} 1,14-24,2015$.

[31] E. Racine, J.L. Troyer, J. Warren-Findlow, W.J. McAuley, The effect of medical nutrition therapy on changes in dietary knowledge and DASH diet adherence in older adults with cardiovascular disease, J. Nutr. Health Aging. Vol.15, $\mathrm{N}^{\circ} 10$, 868-876. 2011

[32] S.C. Couch, B.E. Saelens, L. Levin, K. Dart, G. Falciglia, S.R. Daniels, The efficacy of a clinic-based behavioral nutrition intervention emphasizing a DASH-type diet for adolescents with elevated blood pressure, J. Pediatr. Vol. $152, \mathrm{~N}^{\circ} 4,494-501.2008$

[33] I. Ajzen, The theory of planned behavior: reactions and reflections, Psychol Health. Vol.26, N9 1113-1127. 2011

[34] D. Boucher, C. Gagne, F. Cote, [Determinants of the intention of post-secondary students to eat at least five servings of vegetables and fruit daily], Rev. Epidemiol. Sante Publique. Vol. 60, N², 109-119. 2012

[35] B.M. Popkin. Global nutrition dynamics: the world is shifting rapidly toward a diet linked with non-communicable diseases. Am J Clin Nutr. Vol.84, N², 289-98, 2006.

[36] J.O. Prochaska, W.F. Velicer, The Transtheoretical Model of Health Behavior Change, Am. J. Health Promot. Vol.12, N${ }^{\circ}$, 38-48. 1997

[37] D. Goldman, J. Smith, Can patient self-management help explain SES health gradient?, Proc Natl Acad Sci USA. Vol. 99, $\mathrm{N}^{\circ} 16,10929-10934.2002$

[38] F. Y. Hsieh. Sample size tables for logistic regression. Statistics in medicine, Vol. 8, N7, 795-802. 1989. 